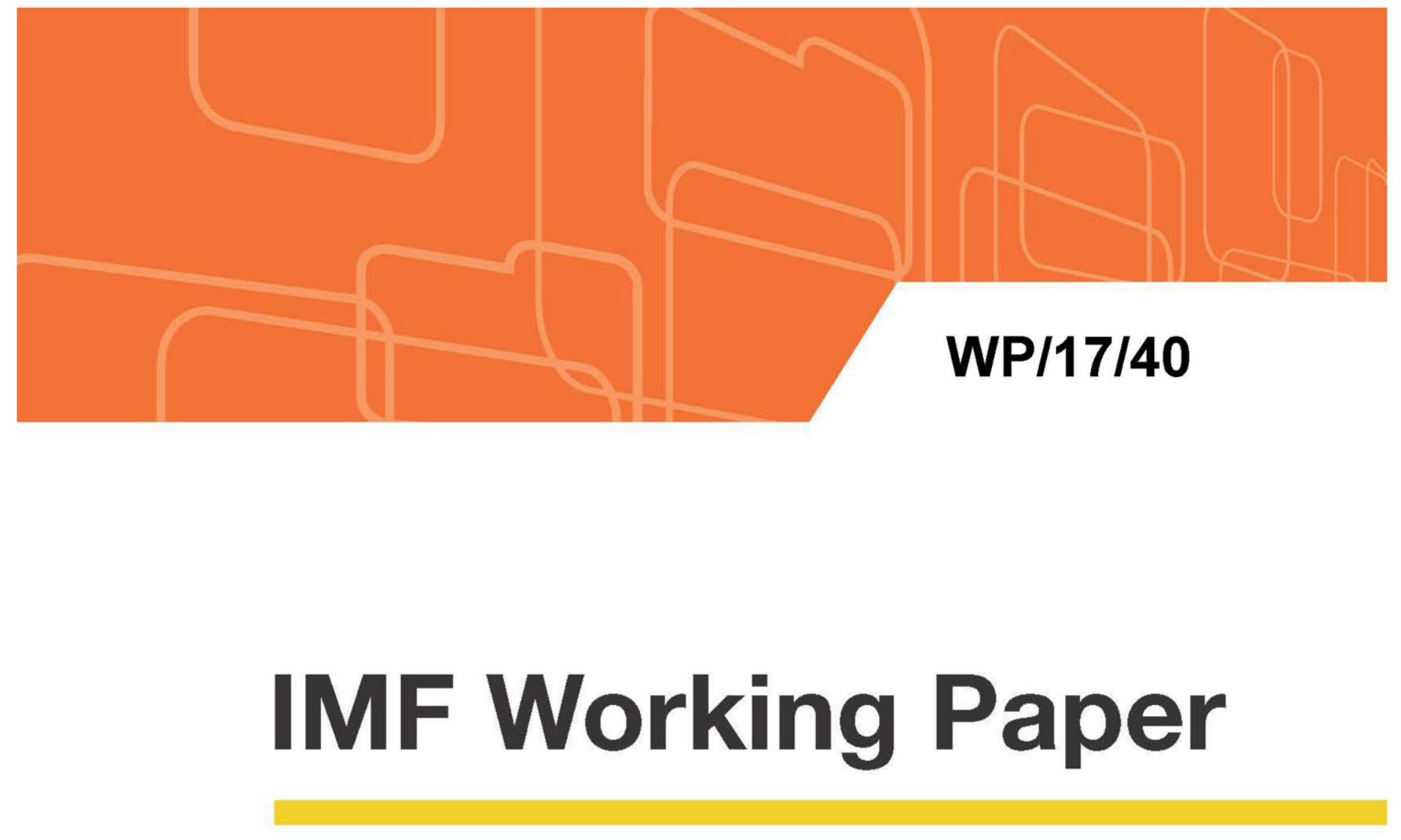

\title{
Sectoral Labor Mobility and Optimal Monetary Policy
}

by Alessandro Cantelmo and Giovanni Melina

IMF Working Papers describe research in progress by the author(s) and are published to elicit comments and to encourage debate. The views expressed in IMF Working Papers are those of the author(s) and do not necessarily represent the views of the IMF, its Executive Board, or IMF management. 


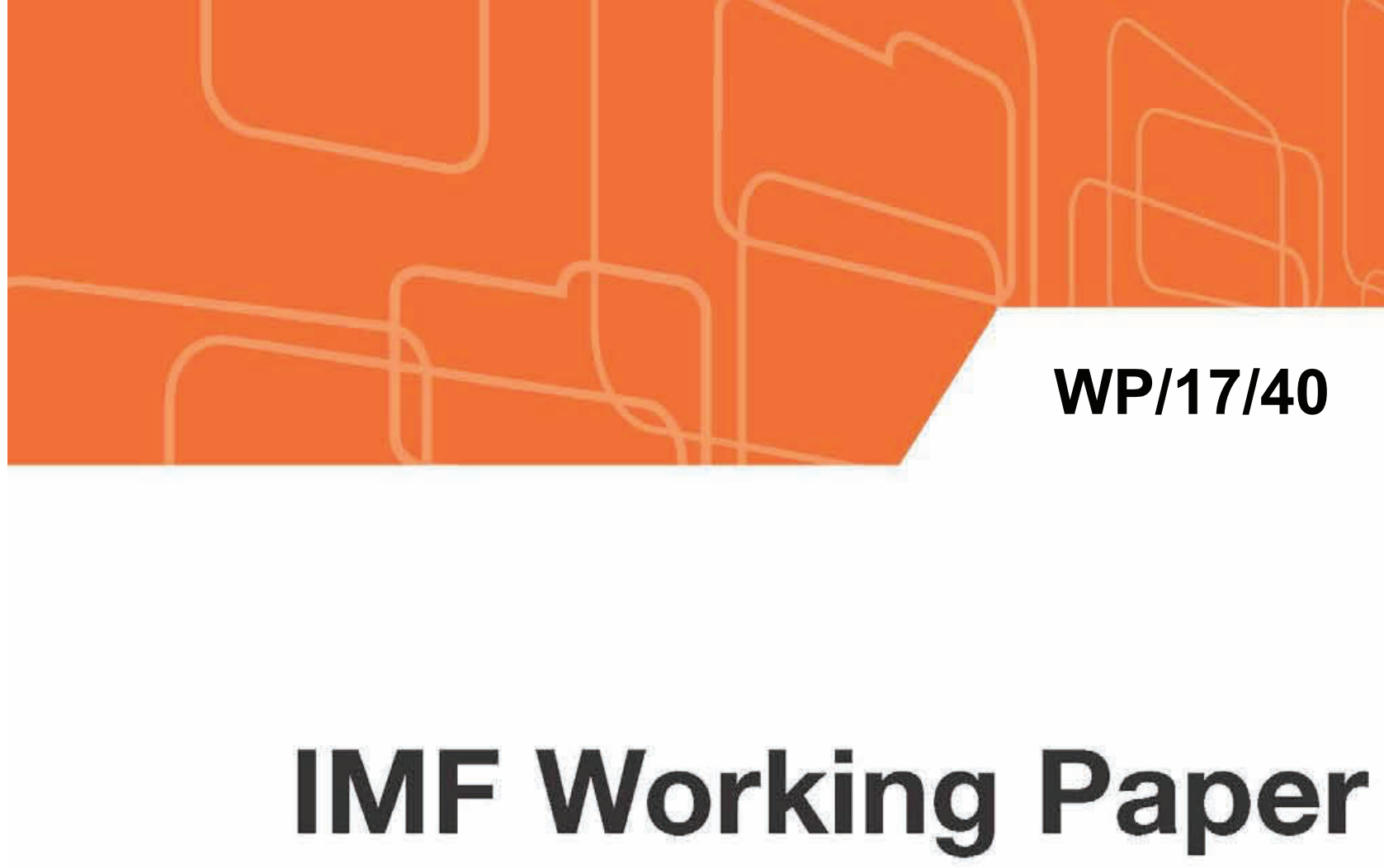

Sectoral Labor Mobility and Optimal Monetary Policy

by Alessandro Cantelmo and Giovanni Melina

IMF Working Papers describe research in progress by the author(s) and are published to elicit comments and to encourage debate. The views expressed in IMF Working Papers are those of the author(s) and do not necessarily represent the views of the IMF, its Executive Board, or IMF management.

I N T ER N A T I O N A L M O NETARY FUND 


\title{
IMF Working Paper
}

Research Department

\section{Sectoral Labor Mobility and Optimal Monetary Policy* \\ Prepared by Alessandro Cantelmo and Giovanni Melina}

Authorized for distribution by Prakash Loungani

March 2017

\section{IMF Working Papers describe research in progress by the author(s) and are published to elicit comments and to encourage debate. The views expressed in IMF Working Papers are those of the author(s) and do not necessarily represent the views of the IMF, its Executive Board, or IMF management.}

\begin{abstract}
In an estimated two-sector New-Keynesian model with durable and nondurable goods, an inverse relationship between sectoral labor mobility and the optimal weight the central bank should attach to durables inflation arises. The combination of nominal wage stickiness and limited labor mobility leads to a nonzero optimal weight for durables inflation even if durables prices were fully flexible. These results survive alternative calibrations and interestrate rules and point toward a non-negligible role of sectoral labor mobility for the conduct of monetary policy.
\end{abstract}

JEL Classification Numbers: E52, E58.

Keywords: Optimal monetary policy, durable goods, labor mobility, DSGE. Author's E-Mail Address: alessandro.cantelmo.1@city.ac.uk; gmelina@imf.org.

\footnotetext{
* Cantelmo: City University of London; Melina: IMF and City University of London. We are grateful to Federico Di Pace, Romain, Duval, Davide Furceri, Paul Levine, Prakash Loungani, Chris Papageorgiou, Joseph Pearlman, Ivan Petrella, and participants at the 2016 IMF-OCP Policy Center-Brunel University Workshop on Global Labor Markets (Paris), the 48th Money Macro and Finance Annual Conference (University of Bath), the ASSET 2016 Annual Meeting (Thessaloniki) and seminars at City, University of London and the IMF for useful comments. All remaining errors are ours.
} 


\section{Contents}

1 Introduction $\quad \underline{5}$

2 Model $\quad \underline{7}$

2.1 Households ......................... $\underline{7}$

2.2 Firms ........................... 10

2.3 Fiscal and monetary policy . . . . . . . . . . . . . . 10

2.4 Market clearing conditions and exogenous processes . . . . . . . . $\underline{11}$

2.5 Functional forms . . . . . . . . . . . . . . . . . . $\underline{12}$

3 Bayesian estimation $\quad \underline{12}$

3.1 Calibration and priors ...................... 13

3.2 Estimation results . . . . . . . . . . . . . . . . . . 14

4 Optimal monetary policy $\quad \underline{16}$

4.1 The monetary policy rule . . . . . . . . . . . . . . . . $\underline{16}$

4.2 Welfare measure . . . . . . . . . . . . . . 17

4.3 Results ........................... 18

4.3.1 Impulse responses to an inflation shock . . . . . . . . . . . $\underline{18}$

4.3.2 Optimized interest-rate rules . . . . . . . . . . . . . . . $\underline{19}$

4.4 Robustness to alternative calibrations and interest rate rules . . . . . $\quad \underline{23}$

5 Conclusion $\quad \underline{24}$

References $\quad \underline{25}$

Appendix $\underline{28}$

A Data $\quad \underline{28}$

A.1 Durables and Residential Investments . . . . . . . . . . . . . 28

A.2 Nondurables and Services . . . . . . . . . . . . . . . 29

A.3 Data transformation for Bayesian estimation . . . . . . . . . $\underline{29}$

B Symmetric equilibrium $\quad \underline{30}$

C Steady state $\quad \underline{32}$ 


\section{List of Tables}

1 Calibrated parameters . . . . . . . . . . . . $\underline{13}$

2 Prior and posterior distributions of estimated parameters . . . . . $\underline{15}$

3 Optimized monetary policy rule: Sticky vs Flexible Durables Prices . . $\underline{20}$

4 Relative standard deviations of inflation, wages and output . . . . . $\underline{22}$

5 Optimized monetary policy rules: robustness to alternative calibrations $\underline{23}$

6 Robustness to alternative optimized monetary policy rule . . . . . . $\underline{24}$

A.1 Data Sources . . . . . . . . . . . . . . . . 28

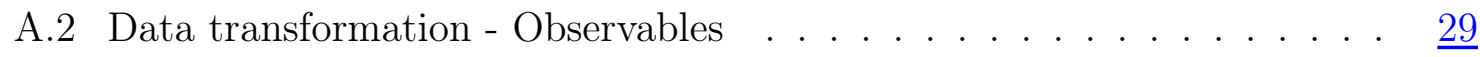

\section{List of Figures}

1 Sectoral labor mobility parameter: prior and posterior densities . . . $\underline{16}$

2 Responses to a durables price markup shock: Ramsey policy . . . . . . 19

3 Durables price stickiness and optimal weight on durables inflation: flexible vs. sticky wages . . . . . . . . . . . . . . . . 21 


\section{Introduction}

What inflation measure should central banks target? This question naturally arises when a New-Keynesian model is extended to include more than one sector. In fact, with only one instrument available, the central bank has to decide how much weight it has to assign to each sectoral inflation.

In a seminal paper, Aoki (2001) studies a two-sector economy with sticky- and flexible-price sectors and finds that, subject only to a technology shock, the central bank should assign zero weight to the flexible-price sector. A similar result is attained by Benigno (2004) in a two-country New-Keynesian model of a currency union which resembles a two-sector model. Here, more weight is attached to inflation in the region displaying a higher degree of price stickiness. Mankiw and Reis (2003) enrich these results by showing that, in order to construct a price index that-if kept on target- stabilizes economic activity, the sectoral weights should depend on the degree of price stickiness, the responsiveness to business cycles and the tendency to experience idiosyncratic shocks.

The optimal monetary policy literature has hitherto augmented a standard twosectors New-Keynesian model by either characterizing the sectors by their durability as in Erceg and Levin (2006), by introducing input-output interactions (I-O, henceforth) between intermediate and final goods firms as in Huang and Liu (2005), or both as in Petrella and Santoro (2011) and Petrella et al. (2016). Abstracting from heterogeneity in price stickiness, Erceg and Levin (2006) show that goods durability plays an important role for the conduct of monetary policy. As durable goods are more sensitive to the interest rate than nondurables, the central bank faces a severe trade-offin stabilizing output and prices across the two sectors. In their setting, with symmetric sectoral price and wage rigidities, the central bank attains the second-best policy by responding to both price and wage inflations. ${ }^{1}$ Conversely, I-O interactions imply that the two sectoral inflations reflect the difference between a consumer price index (CPI) and a producer price index (PPI). In such context, Huang and Liu (2005), Gerberding et al. (2012) and Strum (2009) conclude that targeting hybrid measures of inflation delivers desirable welfare results but the weight assigned to each sectoral inflation reflects their size. Similar conclusions are drawn when, neglecting I-O interactions, durable goods are used as collateral by households to borrow (Monacelli, 2008), sectors differ

\footnotetext{
${ }^{1}$ Consistently, in their empirical exercise, Mankiw and Reis (2003) conclude that substantial weight should be assigned to the level of nominal wages.
} 
by factor intensities (Jeske and Liu, 2013), or the length of wage contracts differs across sectors (Kara, 2010).

All the above-mentioned contributions look at this important issue from many angles, but overlook the role that the extent to which labor is allowed to reallocate across sectors has for optimal monetary policy. Indeed, Petrella et al. (2016) optimally find the weight attached to durables inflation in an input-output economy with a given limited degree of labor mobility, but do not isolate the impact that labor mobility has on the weight itself. We fill this gap and show that the extent to which labor can freely move across sectors is crucial in the determination of the optimal inflation composite, and it intuitively interacts with price and nominal wage stickiness. In our model the two sectors differ both in goods durability and degree of price stickiness, given that durable goods also display less sticky prices in the data, and this empirical regularity is employed in much of the theoretical literature.

We first use Bayesian methods to estimate the model. This embeds imperfect labor mobility, price and wage stickiness and a set of shocks conventional in the monetary policy literature. Model estimates point at a limited degree of labor mobility across sectors. Then, we use the estimated model to design optimized monetary policy rules and highlight a negative relationship between labor mobility and the weight attached to inflation in the durables sector. ${ }^{2}$

Consistently with the literature, a lower weight is assigned to the sector in which prices are more flexible (durables) but, conditional on the degree of price and wage stickiness, such weight is higher the less mobile labor is across sectors. Intuitively, following a shock, the lower (higher) the friction in the labor market the larger (smaller) is the reallocation of workers across sectors hence the smaller (larger) is the adjustment through prices. It follows that the central bank devotes more (less) attention to the stickier sector.

We furthermore show that wage stickiness plays an important role in setting the optimal weight of sectoral inflations due to second-round effects on marginal costs and explains why even with flexible durable prices, the central bank still assigns a positive weight to inflation in the durables sector. Consistently with Erceg and Levin (2006), we also find that key variables in the durables sector are more volatile than in the nondurables sector, specifically the variability of prices, wages and output is higher in the former than in the latter. Finally, when optimizing the parameters of the interest

\footnotetext{
${ }^{2}$ Estimating the model prior to designing optimized monetary policy rules is crucial since, as noted by Cantore et al. (2012), such rules heavily depend on the persistence and the variance of shocks.
} 
rate rule, the central bank actually chooses a price level rule to minimize the welfare loss with respect to the first best policy, a result attained by Levine et al. (2008) and Giannoni (2014), among others, in a one-sector economy. Our results carry an important policy implication: the degree of labor mobility between sectors is an aspect of the economy that central banks should not overlook in setting the monetary policy stance.

The remainder of the paper is organized as follows. Section 2 presents the two-sector New-Keynesian model. In Section 3 we report the results of the Bayesian estimation, whereas Section 4 shows the outcomes of the optimal monetary policy exercises. Finally, Section 5 concludes. More details about the data, the model's equilibrium conditions and the steady state are provided in the Appendix.

\section{Model}

We construct a two-sector New-Keynesian model in the spirit of Barsky et al. (2007), where consumers purchase both durable and nondurable goods. In addition, there are several frictions now standard in the New-Keynesian literature, namely price and wage stickiness, investment adjustment costs in durable goods (IAC, henceforth), habit formation in consumption of nondurable goods. We also introduce imperfect labor mobility across sectors and estimate the relevant parameter. Finally, the monetary authority sets the nominal interest rate according to an interest rate rule.

\subsection{Households}

There is a continuum $i \in[0,1]$ of identical and infinitely-lived households consuming both durable and nondurable goods and supplying labor, whose lifetime utility is

$$
E_{0} \sum_{t=0}^{\infty} e_{t}^{B} \beta^{t} U\left(X_{i, t}, N_{i, t}\right)
$$

where $\beta \in[0,1]$ is the subjective discount factor, $e_{t}^{B}$ is a preference shock, $X_{i, t}=$ $Z_{i, t}^{1-\alpha} D_{i, t}^{\alpha}$ is a Cobb-Douglas consumption aggregator of nondurable $\left(Z_{i, t}\right)$ and durable goods $\left(D_{i, t}\right)$ with $\alpha \in[0,1]$ representing the share of durables consumption on total expenditure, and $N_{i, t}$ being the household's labor supply. Nondurable consumption is 
subject to external habit formation such that

$$
\begin{aligned}
Z_{i, t} & =C_{i, t}-\zeta S_{t-1}, \\
S_{t} & =\rho_{c} S_{t-1}+\left(1-\rho_{c}\right) C_{t},
\end{aligned}
$$

where $C_{i, t}$ is the level of the household's nondurable consumption; $S_{t}, \zeta \in(0,1)$ and $\rho_{c} \in(0,1)$ are the stock, the degree and the persistence of habit formation, respectively, while $C_{t}$ represents average consumption across households. Members of each household supply labor to firms in both sectors according to:

$$
N_{i, t}=\left[\left(\chi^{C}\right)^{-\frac{1}{\lambda}}\left(N_{i, t}^{C}\right)^{\frac{1+\lambda}{\lambda}}+\left(1-\chi^{C}\right)^{-\frac{1}{\lambda}}\left(N_{i, t}^{D}\right)^{\frac{1+\lambda}{\lambda}}\right]^{\frac{\lambda}{1+\lambda}}
$$

Following Horvath (2000), Petrella and Santoro (2011) and Petrella et al. (2016), this CES specification of aggregate labor captures different degrees of labor mobility across sectors, governed by parameter $\lambda>0$, i.e. the intra-temporal elasticity of substitution: $\lambda \rightarrow 0$ denotes the case of labor immobility, while as $\lambda \rightarrow \infty$ labor can be freely reallocated and all workers earn the same wage at the margin. For $\lambda<\infty$ the economy displays a limited degree of labor mobility and sectoral wages are not equal. ${ }^{3}$ Moreover, $\chi^{C} \equiv N^{C} / N$ represents the steady-state share of labor supply in the nondurables sector. The stock of durables evolves according to law of motion

$$
D_{i, t+1}=(1-\delta) D_{i, t}+e_{t}^{I} I_{i, t}^{D}\left[1-S\left(\frac{I_{i, t}^{D}}{I_{i, t-1}^{D}}\right)\right]
$$

where $\delta$ is the depreciation rate, $I_{i, t}^{D}$ is investment in durable goods that is subject to adjustment costs, and $e_{t}^{I}$ represents an investment-specific shock. The adjustment costs function $S(\cdot)$ satisfies $S(1)=S^{\prime}(1)=0$ and $S^{\prime \prime}(1)>0$. Each household consumes $C_{i, t}$, purchases nominal bonds $B_{i, t}$, receives profits $\Omega_{t}$ from firms and pays a lump-sum tax $T_{t}$. Finally, $Q_{t} \equiv \frac{P_{D, t}}{P_{C, t}}$ denotes the relative price of durables so that the period-by-period real budget constraint reads as follows:

\footnotetext{
${ }^{3}$ According to Horvath (2000), the CES aggregator allows us to capture labor market mobility without deviating from the representative agent assumption. Di Pace and Hertweck (2016) show that search and matching frictions improve the fit of a two-sector model to the data but, although desirable, capturing sectoral labor market mobility in a search and matching framework is not straightforward and would inevitably complicate our analysis.
} 


$$
C_{i, t}+Q_{t} I_{i, t}^{D}+\frac{\vartheta^{W}}{2}\left(\frac{w_{i, t}}{w_{i, t-1}} \Pi_{t}^{C}-\Pi^{C}\right)^{2} w_{t} N_{t}+\frac{B_{i, t}}{P_{t}^{C}}=\frac{W_{i, t}}{P_{t}^{C}} N_{i, t}+R_{t-1} \frac{B_{i, t-1}}{P_{t}^{C}}+\Omega_{t}-T_{t},
$$

where the term $\frac{\vartheta^{W}}{2}\left(\frac{w_{i, t}}{w_{i, t-1}} \Pi_{t}^{C}-\Pi^{C}\right)^{2} w_{t} N_{t}$ accounts for nominal wage adjustment costs à la Rotemberg (1982). Households choose $Z_{i, t}, B_{i, t}, D_{i, t+1}, I_{i, t}^{D}, w_{i, t}, N_{i, t}^{C}, N_{i, t}^{D}$ to maximize (1) subject to (2), (3), (4), (5) and (6).

At the symmetric equilibrium, the household's optimality conditions are:

$$
\begin{aligned}
1= & E_{t}\left[\Lambda_{t, t+1} \frac{R_{t}}{\Pi_{t+1}^{C}}\right], \\
Q_{t} \psi_{t}= & \frac{U_{D, t}}{U_{Z, t}}+(1-\delta) E_{t}\left[\Lambda_{t, t+1} Q_{t+1} \psi_{t+1}\right], \\
1= & \psi_{t} e_{t}^{I}\left[1-S\left(\frac{I_{t}^{D}}{I_{t-1}^{D}}\right)-S^{\prime}\left(\frac{I_{t}^{D}}{I_{t-1}^{D}}\right) \frac{I_{t}^{D}}{I_{t-1}^{D}}\right]+ \\
& +E_{t}\left\{\Lambda_{t, t+1} \psi_{t+1} \frac{Q_{t+1}}{Q_{t}} e_{t+1}^{I}\left[S^{\prime}\left(\frac{I_{t+1}^{D}}{I_{t}^{D}}\right)\left(\frac{I_{t+1}^{D}}{I_{t}^{D}}\right)^{2}\right]\right\}, \\
N_{t}^{C}= & \chi^{C}\left(\frac{w_{t}^{C}}{w_{t}}\right)^{\lambda} N_{t}, \\
N_{t}^{D}= & \chi^{D}\left(\frac{w_{t}^{D}}{w_{t}}\right)^{\lambda} N_{t}, \\
0= & {\left[1-e_{t}^{W} \eta\right]+\frac{e_{t}^{W} \eta}{\tilde{\mu}_{t}}-\vartheta^{W}\left(\Pi_{t}^{W}-\Pi^{C}\right) \Pi_{t}^{W}+} \\
& +E_{t}\left[\Lambda_{t, t+1} \vartheta^{W}\left(\Pi_{t+1}^{W}-\Pi^{C}\right) \Pi_{t+1}^{W} \frac{w_{t+1} N_{t+1}}{w_{t} N_{t}}\right] .
\end{aligned}
$$

Equation (7) is a standard Euler equation with $\Lambda_{t, t+1} \equiv \beta \frac{U_{Z, t+1}}{U_{Z, t}} \frac{e_{t+1}^{B}}{e_{t}^{B}}$ representing the stochastic discount factor and $U_{Z, t}$ denoting the marginal utility of habit-adjusted consumption of nondurable goods. Equation (8) represents the asset price of durables, where $U_{D, t}$ is the marginal utility of durables consumption and $\psi_{t}$ is the Lagrange multiplier attached to constraint (5). Equation (10) is the optimality condition w.r.t. investment in durable goods. Equations (11) and (12) are the household's labor supplies in each sector, whereas equation (13) is the wage setting equation in which $\tilde{\mu}_{t} \equiv \frac{w_{t}}{M R S_{t}}$ is the wage markup, $M R S_{t} \equiv-\frac{U_{N, t}}{U_{Z, t}}$ is the marginal rate of substitution between consumption and leisure, $U_{N, t}$ is the marginal disutility of work and $\Pi_{t}^{W}$ is the gross wage inflation rate. 


\subsection{Firms}

A continuum $\omega \in[0,1]$ of firms in each sector $j=C, D$ operates in monopolistic competition and face quadratic costs of changing prices $\frac{\vartheta_{j}}{2}\left(\frac{P_{\omega, t}^{j}}{P_{\omega, t-1}^{j}}-1\right)^{2} Y_{t}^{j}$, where $\vartheta_{j}$ is the parameter of sectoral price stickiness. Each firm produces differentiated goods according to a linear production function,

$$
Y_{\omega, t}^{j}=e_{t}^{A} N_{\omega, t}^{j}
$$

where $e_{t}^{A}$ is a labor-augmenting productivity shock. Firms maximize the present discounted value of profits,

$$
E_{t}\left\{\sum_{t=0}^{\infty} \Lambda_{t, t+1}\left[\frac{P_{\omega, t}^{j}}{P_{t}^{j}} Y_{\omega, t}^{j}-\frac{W_{\omega t}}{P_{t}^{j}} N_{\omega, t}^{j}-\frac{\vartheta_{j}}{2}\left(\frac{P_{\omega, t}^{j}}{P_{\omega, t-1}^{j}}-1\right)^{2} Y_{t}^{j}\right]\right\}
$$

subject to production function (14) and a standard Dixit-Stiglitz demand equation $Y_{\omega, t}^{j}=\left(\frac{P_{\omega, t}^{j}}{P_{t}^{j}}\right)^{-e_{t}^{j} \epsilon_{j}} Y_{t}^{j}$, where $\epsilon_{j}$ and $e_{t}^{j}$ are the sectoral intratemporal elasticity of substitution across goods and the sectoral price markup shock, respectively. At the symmetric equilibrium, the price setting equations for the two sectors read as

$$
\begin{gathered}
\left(1-e_{t}^{C} \epsilon_{c}\right)+e_{t}^{C} \epsilon_{c} M C_{t}^{C}-\vartheta_{c}\left(\Pi_{t}^{C}-1\right) \Pi_{t}^{C}= \\
=\vartheta_{c} E_{t}\left[\Lambda_{t, t+1} \frac{Y_{t+1}^{C}}{Y_{t}^{C}}\left(\Pi_{t+1}^{C}-1\right) \Pi_{t+1}^{C}\right], \\
\left(1-e_{t}^{D} \epsilon_{d}\right)+e_{t}^{D} \epsilon_{d} M C_{t}^{D}-\vartheta_{d}\left(\Pi_{t}^{D}-1\right) \Pi_{t}^{D}= \\
=\vartheta_{d} E_{t}\left[\Lambda_{t, t+1} \frac{Q_{t+1}}{Q_{t}} \frac{Y_{t+1}^{D}}{Y_{t}^{D}}\left(\Pi_{t+1}^{D}-1\right) \Pi_{t+1}^{D}\right],
\end{gathered}
$$

where $M C_{t}^{C}=\frac{w_{t}}{e_{t}^{t}}$ and $M C_{t}^{D}=\frac{w_{t}}{e_{t}^{A} Q_{t}}$. When $\vartheta_{j}=0$ prices are fully flexible and are set as constant markups over the marginal costs.

\section{$2.3 \quad$ Fiscal and monetary policy}

The government purchases nondurable goods as in Erceg and Levin (2006) and runs a balanced budget by levying lump-sum taxes. Monetary policy is conducted by an independent central bank via the following interest rate rule: 


$$
\begin{aligned}
\log \left(\frac{R_{t}}{\bar{R}}\right) & =\rho_{r} \log \left(\frac{R_{t-1}}{\bar{R}}\right)+\left(1-\rho_{r}\right)\left\{\rho_{\pi} \log \left(\frac{\tilde{\Pi}_{t}}{\tilde{\Pi}}\right)+\rho_{y} \log \left(\frac{Y_{t}}{Y_{t}^{f}}\right)\right. \\
& \left.+\rho_{\Delta y}\left[\log \left(\frac{Y_{t}}{Y_{t}^{f}}\right)-\log \left(\frac{Y_{t-1}}{Y_{t-1}^{f}}\right)\right]\right\}+e_{t}^{R} .
\end{aligned}
$$

Equation (18) is that employed by Smets and Wouters (2007) and implies that the central bank reacts to inflation, the output gap and the output gap growth to an extent determined by parameters $\rho_{\pi}, \rho_{y}$ and $\rho_{\Delta y}$, respectively. The output gap is defined as the deviation of output from the level that would prevail with flexible prices and wages, $Y_{t}^{f}$, and $\rho_{r}$ is the degree of interest rate smoothing. The variable

$$
\widetilde{\Pi}_{t} \equiv\left(\Pi_{t}^{C}\right)^{1-\tau}\left(\Pi_{t}^{D}\right)^{\tau}
$$

is an aggregator of the gross rates of sectoral inflations, $\widetilde{\Pi}$ is its steady-state value, and $\tau \in[0,1]$ represents the weight assigned by the central bank to durables inflation.

\subsection{Market clearing conditions and exogenous processes}

In equilibrium all markets clear and the model is closed by the following identities:

$$
\begin{aligned}
Y_{t}^{C} & =C_{t}+e_{t}^{G}+\frac{\vartheta_{c}}{2}\left(\Pi_{t}^{C}-\Pi^{C}\right)^{2} Y_{t}^{C}, \\
Y_{t}^{D} & =\left[D_{t}-(1-\delta) D_{t-1}\right]+\frac{\vartheta_{d}}{2}\left(\Pi_{t}^{D}-\Pi^{D}\right)^{2} Y_{t}^{D}, \\
Y_{t} & =Y_{t}^{C}+Q_{t} Y_{t}^{D}+\frac{\vartheta^{W}}{2}\left(\frac{w_{t}}{w_{t-1}} \Pi_{t}^{C}-\Pi^{C}\right)^{2} w_{t} N_{t} .
\end{aligned}
$$

As in Smets and Wouters (2007), the wage markup and the price markup shocks follow ARMA (1,1) processes:

$$
\log \left(\frac{\varkappa_{t}}{\bar{\varkappa}}\right)=\rho_{\varkappa} \log \left(\frac{\varkappa_{t-1}}{\bar{\varkappa}}\right)+\epsilon_{t}^{\varkappa}-\theta_{i} \epsilon_{t-1}^{\varkappa},
$$

with $\varkappa=\left[e^{W}, e^{C}, e^{D}\right], i=[W, C, D]$, whereas all other shocks follow an AR (1) process:

$$
\log \left(\frac{\kappa_{t}}{\bar{\kappa}}\right)=\rho_{\kappa} \log \left(\frac{\kappa_{t-1}}{\bar{\kappa}}\right)+\epsilon_{t}^{\kappa}
$$


where $\kappa=\left[e^{B}, e^{I}, e^{R}, e^{A}, e^{G}\right]$ is a vector of exogenous variables, $\rho_{\varkappa}$ and $\rho_{\kappa}$ are the autoregressive parameters, $\theta_{i}$ are the moving average parameters, $\epsilon_{t}^{\varkappa}$ and $\epsilon_{t}^{\kappa}$ are i.i.d shocks with zero mean and standard deviations $\sigma_{\varkappa}$ and $\sigma_{\kappa}$.

\subsection{Functional forms}

The utility function is additively separable and logarithmic in consumption: $U\left(X_{t}, N_{t}\right)=$ $\log \left(X_{t}\right)-\nu \frac{N_{t}^{1+\varphi}}{1+\varphi}$, where $\nu$ is a scaling parameter for hours worked and $\varphi$ is the inverse of the Frisch elasticity of labor supply. Adjustment costs in durables investment are quadratic: $S\left(\frac{I_{t}^{D}}{I_{t-1}^{D}}\right)=\frac{\phi}{2}\left(\frac{I_{t}^{D}}{I_{t-1}^{D}}-1\right)^{2}, \phi>0$ as in Christiano et al. (2005).

\section{Bayesian estimation}

The model is estimated with Bayesian methods. The Kalman filter is used to evaluate the likelihood function that, combined with the prior distribution of the parameters, yields the posterior distribution. Then, the Monte-Carlo-Markov-Chain MetropolisHastings (MCMC-MH) algorithm with two parallel chains of 150,000 draws each is used to generate a sample from the posterior distribution in order to perform inference. We estimate the model over the sample 1969Q2-2007Q4 by using US data on: GDP, consumption of durable goods, consumption of nondurable goods, real wage, hours worked, inflation in the nondurables sector, inflation in the durables sector and the nominal interest rate. The following measurement equations link the data to the endogenous variables of the model:

$$
\begin{aligned}
\Delta Y_{t}^{o} & =\gamma+\hat{Y}_{t}-\hat{Y}_{t-1}, \\
\Delta I_{D, t}^{o} & =\gamma+\hat{I}_{D, t}-\hat{I}_{D, t-1}, \\
\Delta C_{t}^{o} & =\gamma+\hat{C}_{t}-\hat{C}_{t-1}, \\
\Delta W_{t}^{o} & =\gamma+\hat{W}_{t}-\hat{W}_{t-1}, \\
N_{t}^{o} & =\hat{N}_{t}, \\
\Pi_{C, t}^{o} & =\bar{\pi}_{C}+\hat{\Pi}_{t}^{C}, \\
\Pi_{D, t}^{o} & =\bar{\pi}_{D}+\hat{\Pi}_{t}^{D}, \\
R_{t}^{o} & =\bar{r}+\hat{R}_{t},
\end{aligned}
$$




\begin{tabular}{lll}
\hline Parameter & & Value \\
\hline Discount factor & $\beta$ & 0.99 \\
Durables depreciation rate & $\delta$ & 0.010 \\
Durables share of total expenditure & $\alpha$ & 0.20 \\
Elasticity of substitution nondurable goods & $\epsilon_{c}$ & 6 \\
Elasticity of substitution durable goods & $\epsilon_{d}$ & 6 \\
Elasticity of substitution in labor & $\eta$ & 21 \\
Preference parameter & $\nu$ & set to target $\bar{N}=0.33$ \\
Government share of output & $g_{y}$ & 0.20 \\
\hline
\end{tabular}

Table 1: Calibrated parameters

where $\gamma$ is the common quarterly trend growth rate of GDP, consumption of durables, consumption of nondurables and the real wage; $\bar{\pi}_{C}$ and $\bar{\pi}_{D}$ are the average quarterly inflation rates in nondurable and durable sectors respectively; $\bar{r}$ is the average quarterly Federal funds rate. Hours worked are demeaned so no constant is required in the corresponding measurement equation (29). Variables with a ^ are in log-deviations from their own steady state.

\subsection{Calibration and priors}

Table 1 presents the structural parameters calibrated at a quarterly frequency. The discount factor $\beta$ is equal to the conventional value of 0.99 , implying an annual steadystate gross interest rate of $4 \%$. Following Monacelli (2009), we calibrate the depreciation rate of durable goods $\delta$ at 0.010 amounting to an annual depreciation of $4 \%$, and the durables share of total expenditure $\alpha$ is set at 0.20 . The sectoral elasticities of substitution across different varieties $\epsilon_{c}$ and $\epsilon_{d}$ equal 6 in order to target a steady-state gross mark-up of 1.20 in both sectors. We target a $5 \%$ steady-state gross wage markup hence we set the elasticity of substitution in the labor market $\eta$ equal to 21 as in Zubairy (2014). The preference parameter $\nu$ is set to target steady-state total hours of work of 0.33 . The government-output ratio $g_{y}$ is calibrated at 0.20 , in line with the data.

Prior and posterior distributions of the parameters and the shocks are reported in Table 2. We set the prior mean of the inverse Frisch elasticity $\varphi$ to 0.5 , broadly in line with Smets and Wouters (2007, SW henceforth) who estimate a Frisch elasticity of 1.92. We also follow $\mathrm{SW}$ in setting the prior means of the habit parameter, $\zeta$, to 0.7 , the interest rate smoothing parameter, $\rho_{r}$, to 0.80 and in assuming a stronger response 
of the central bank to inflation than output. We set the prior means of the constants in the measurement equations equal to the average values in the dataset. In general, we use the Beta distribution for all parameters bounded between 0 and 1 . We use the Inverse Gamma (IG) distribution for the standard deviation of the shocks for which we set a loose prior with 2 degrees of freedom. We choose a Gamma distribution for the Rotemberg parameters for both prices and wages, given that these are non-negative. The price stickiness parameters are assigned the same prior distribution corresponding to firms resetting prices around 1.5 quarters on average in a Calvo world. Finally, we follow Iacoviello and Neri (2010) who choose a Normal distribution for the intratemporal elasticity of substitution in labor supply $\lambda$, with a prior mean of 1 which implies a limited degree of labor mobility.

\subsection{Estimation results}

We report the posterior mean of the parameters together with the $90 \%$ probability intervals in square brackets in Table 2. We first devote our attention to the parameters that will be crucial for remainder of the analysis. In line with the literature, the labor mobility parameter $\lambda$ is estimated to be 1.1769 implying a non-negligible degree of friction in the labor market. Indeed, Horvath (2000) estimates a regression equation to find a value of 0.999 whereas Iacoviello and Neri (2010) estimate values of 1.51 and 1.03 for savers and borrowers, respectively. ${ }^{4}$ Typically, limited labor mobility is calibrated at a value of $\lambda=1$ (see Bouakez et al. 2009, Petrella and Santoro 2011 and Petrella et al. 2016) except Bouakez et al. (2011) who explore values between 0.5 and 1.5. Figure 1 displays the prior and posterior distribution of $\lambda$ to confirm that the parameter is correctly identified as the posterior distribution is rather apart from the prior and that it includes the above-mentioned values used in the literature.

Prices are estimated to be stickier in the nondurables sector, with a non-negligible degree of stickiness in durable goods. In the literature there is no decisive evidence that prices of nondurable goods are much stickier than those of many durables (see Bils and Klenow, 2004 and Nakamura and Steinsson, 2008, among others).$^{5}$

\footnotetext{
${ }^{4}$ Iacoviello and Neri (2010) specify the CES aggregator such that the labor mobility parameter is the inverse of $\lambda$. They find values of 0.66 and 0.97 for savers and borrowers respectively hence the values of $1 / 0.66=1.51$ and $1 / 0.97=1.03$ we reported to ease the comparison.

${ }^{5}$ Bouakez et al. (2014), Cantelmo and Melina (2015) and the references therein provide a more detailed discussion about the macro and micro evidence of sectoral price stickiness.
} 


\begin{tabular}{|c|c|c|c|c|c|}
\hline \multirow[t]{2}{*}{ Parameter } & & \multicolumn{3}{|c|}{ Prior } & \multirow[t]{2}{*}{ Posterior Mean } \\
\hline & & Distrib. & Mean & $\mathrm{Std} / \mathrm{df}$ & \\
\hline \multicolumn{6}{|l|}{ Structural } \\
\hline Labor mobility & $\lambda$ & Normal & 1.00 & 0.10 & $1.1769[1.0327 ; 1.3228]$ \\
\hline Inverse Frisch elasticity & $\varphi$ & Normal & 0.50 & 0.10 & $0.572[0.4137 ; 0.7233]$ \\
\hline Habit in nondurables consumption & $\zeta$ & Beta & 0.70 & 0.10 & $0.7931[0.7573 ; 0.8293]$ \\
\hline Habit persist. nondurables consumption & $\rho_{c}$ & Beta & 0.70 & 0.10 & $0.4306[0.3315 ; 0.5321]$ \\
\hline Price stickiness nondurables & $\vartheta_{c}$ & Gamma & 15.0 & 5.00 & $37.4735[26.6634 ; 47.5440]$ \\
\hline Price stickiness durables & $\vartheta_{d}$ & Gamma & 15.0 & 5.00 & $35.9731[26.0116 ; 45.6557]$ \\
\hline Wage stickiness & $\vartheta^{W}$ & Gamma & 100.0 & 10.00 & $102.6213[86.5891 ; 119.363]$ \\
\hline Invest. adjust. costs durable goods & $\phi$ & Normal & 1.5 & 0.50 & $2.2812[1.6753 ; 2.8612]$ \\
\hline Share of durables inflation in aggregator & $\tau$ & Beta & 0.20 & 0.10 & $0.2001[0.1179 ; 0.2838]$ \\
\hline Inflation -Taylor rule & $\rho_{\pi}$ & Normal & 1.50 & 0.20 & $1.6388[1.4600 ; 1.8302]$ \\
\hline Output -Taylor rule & $\rho_{y}$ & Gamma & 0.10 & 0.05 & $0.0646[0.0307 ; 0.0953]$ \\
\hline Output growth -Taylor rule & $\rho_{\Delta y}$ & Gamma & 0.10 & 0.05 & $0.2904[0.0867 ; 0.4756]$ \\
\hline Interest rate smoothing & $\rho_{r}$ & Beta & 0.80 & 0.10 & $0.7015[0.6543 ; 0.7481]$ \\
\hline \multicolumn{6}{|l|}{ Averages } \\
\hline Trend growth rate & $\gamma$ & Normal & 0.49 & 0.10 & $0.3988[0.3794 ; 0.4192]$ \\
\hline Inflation rate nondurables & $\bar{\pi}_{C}$ & Gamma & 1.05 & 0.10 & $1.0298[0.9396 ; 1.1210]$ \\
\hline Inflation rate durables & $\bar{\pi}_{D}$ & Gamma & 0.55 & 0.10 & $0.5330[0.4414 ; 0.6288]$ \\
\hline Interest rate & $\bar{r}$ & Gamma & 1.65 & 0.10 & $1.6225[1.5002 ; 1.7420]$ \\
\hline \multicolumn{6}{|l|}{ Exogenous processes } \\
\hline \multirow[t]{2}{*}{ Technology } & $\rho_{e^{A}}$ & Beta & 0.50 & 0.20 & $0.9258[0.8943 ; 0.9563]$ \\
\hline & $\sigma_{e^{A}}$ & IG & 0.10 & 2.0 & $0.0070[0.0064 ; 0.0077]$ \\
\hline \multirow[t]{2}{*}{ Monetary Policy } & $\rho_{e^{R}}$ & Beta & 0.50 & 0.20 & $0.1355[0.0423 ; 0.2217]$ \\
\hline & $\sigma_{e^{R}}$ & IG & 0.10 & 2.0 & $0.0029[0.0025 ; 0.0032]$ \\
\hline \multirow[t]{2}{*}{ Investment Durables } & $\rho_{e^{I}}$ & Beta & 0.50 & 0.20 & $0.2653[0.1342 ; 0.4042]$ \\
\hline & $\sigma_{e^{I}}$ & IG & 0.10 & 2.0 & $0.0585[0.0413 ; 0.0752]$ \\
\hline \multirow[t]{2}{*}{ Preference } & $\rho_{e^{B}}$ & Beta & 0.50 & 0.20 & $0.6450[0.5536 ; 0.7388]$ \\
\hline & $\sigma_{e^{B}}$ & $\mathrm{IG}$ & 0.10 & 2.0 & $0.0192[0.0159 ; 0.0222]$ \\
\hline \multirow[t]{3}{*}{ Price mark-up nondurables } & $\rho_{e} C$ & Beta & 0.50 & 0.20 & $0.9454[0.9091 ; 0.9822]$ \\
\hline & $\theta_{C}$ & Beta & 0.50 & 0.20 & $0.4130[0.2347 ; 0.5897]$ \\
\hline & $\sigma_{e^{C}}$ & IG & 0.10 & 2.0 & $0.0201[0.0151 ; 0.0251]$ \\
\hline \multirow[t]{3}{*}{ Price mark-up durables } & $\rho_{e^{D}}$ & Beta & 0.50 & 0.20 & $0.9797[0.9641 ; 0.9951]$ \\
\hline & $\theta_{D}$ & Beta & 0.50 & 0.20 & $0.1650[0.0392 ; 0.2827]$ \\
\hline & $\sigma_{e^{D}}$ & $\mathrm{IG}$ & 0.10 & 2.0 & $0.0556[0.0444 ; 0.0657]$ \\
\hline \multirow[t]{3}{*}{ Wage mark-up } & $\rho_{e} W$ & Beta & 0.50 & 0.20 & $0.9694[0.9495 ; 0.9922]$ \\
\hline & $\theta_{W}$ & Beta & 0.50 & 0.20 & $0.5414[0.4313 ; 0.6544]$ \\
\hline & $\sigma_{e} W$ & IG & 0.10 & 2.0 & $0.0408[0.0341 ; 0.0477]$ \\
\hline \multirow[t]{2}{*}{ Government spending } & $\rho_{e^{G}}$ & Beta & 0.50 & 0.20 & $0.9398[0.9077 ; 0.9743]$ \\
\hline & $\sigma_{e^{G}}$ & IG & 0.10 & 2.0 & $0.0355[0.0322 ; 0.0387]$ \\
\hline Log-marginal likelihood & & & & & -1378.927 \\
\hline
\end{tabular}

Table 2: Prior and posterior distributions of estimated parameters 


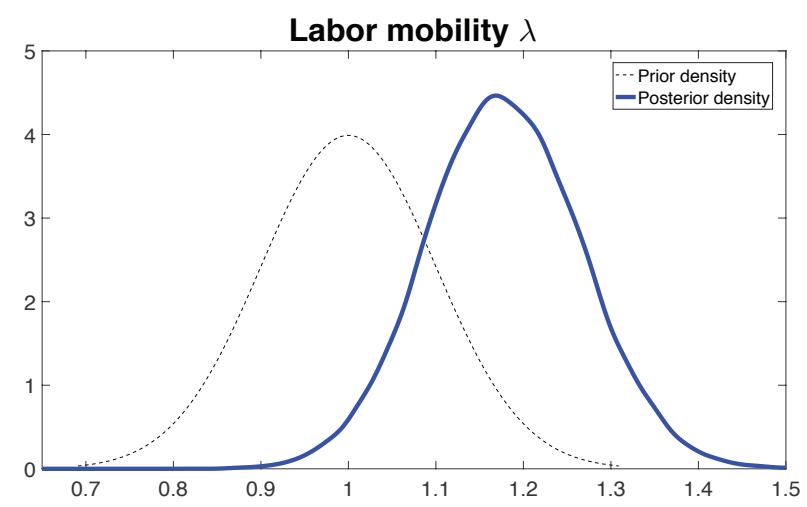

Figure 1: Sectoral labor mobility parameter: prior and posterior densities

However, prices of new houses are generally rather flexible. Therefore, given the importance of the degree of price stickiness of durable goods for our results, in the remainder of the paper we use both the estimated value in the baseline model and alternative calibrations. Similarly, wages are found to be sticky but we also explore the effects of flexible wages.

The remaining parameters are broadly in line with the literature and suggest a relevance of the real frictions (IAC in durable goods and habits in consumption of nondurables) and a stronger response of monetary policy to inflation with respect to output with a high degree of policy inertia. Overall, our estimation delivers results consistent with both standard and two-sectors New-Keynesian models estimated with Bayesian methods and serves as the starting point for our analysis of optimal monetary policy.

\section{Optimal monetary policy}

\subsection{The monetary policy rule}

To design the optimal monetary policy, we reparametrize the interest rate rule (18) as

$$
\begin{aligned}
\log \left(\frac{R_{t}}{\bar{R}}\right) & =\rho_{r} \log \left(\frac{R_{t-1}}{\bar{R}}\right)+\alpha_{\pi} \log \left(\frac{\tilde{\Pi}_{t}}{\tilde{\Pi}}\right)+ \\
& +\alpha_{y} \log \left(\frac{Y_{t}}{Y_{t}^{f}}\right)+\alpha_{\Delta y}\left[\log \left(\frac{Y_{t}}{Y_{t}^{f}}\right)-\log \left(\frac{Y_{t-1}}{Y_{t-1}^{f}}\right)\right],
\end{aligned}
$$


with $\alpha_{\pi} \equiv\left(1-\rho_{r}\right) \rho_{\pi}, \alpha_{y} \equiv\left(1-\rho_{r}\right) \rho_{y}, \alpha_{\triangle y} \equiv\left(1-\rho_{r}\right) \rho_{\Delta y}$, to include the case of price-level rules in the spirit of Woodford (2003) and Giannoni (2014) when $\rho_{r}=1 .^{6}$ In Section 4.4 we assess also the robustness of our results to a superinertial rule in which $\rho_{r}>1$ and to an alternative rule that responds only to inflation and deviations of output from its steady state.

\subsection{Welfare measure}

The optimal monetary policy analysis serves two purposes: (i) determining the optimal weights the central bank should assign to sectoral inflations subject to given degrees of labor mobility, and (ii) seeking parameter values for interest rate rule (33) to mimic the first best allocation, i.e. that minimize the welfare loss with respect to the Ramsey policy. The social planner maximizes the present value of households' utility,

$$
\Upsilon_{t}=E_{t}\left[\sum_{s=0}^{\infty} e_{s}^{B} \beta^{s} U\left(X_{t+s}, N_{t+s}\right)-w_{r}\left(R_{t+s}-R\right)^{2}\right]
$$

subject to the equilibrium conditions of the model. As established by Schmitt-Grohe and Uribe (2007), while more stylized models allow for a first-order approximation to the equilibrium conditions to be sufficient to accurately approximate welfare up to a second order, the presence of numerous frictions requires taking a second-order approximation both of the mean of $\Upsilon_{t}$ and of the model's equilibrium conditions around the deterministic steady state. In particular, we take the approximation around the steady state of the Ramsey equilibrium. Similarly to many other NK models in the literature (see e.g. Schmitt-Grohe and Uribe, 2007; Levine et al., 2008, among others), the steady-state value of the gross inflation rate in the Ramsey equilibrium turns out to be very close to unity, which implies an almost zero-inflation steady state.

Since it is not straightforward to account for the zero-lower-bound (ZLB, henceforth) on the nominal interest rate when using perturbation methods, we follow SchmittGrohe and Uribe (2007) and Levine et al. (2008) and introduce a term in (34) that penalizes large deviations of the nominal interest rate from its steady state. Hence, the imposition of this approximate ZLB constraint translates into appropriately choosing the weight $w_{r}$ to achieve an arbitrarily low per-period probability of hitting the ZLB, $\operatorname{Pr}(Z L B) \equiv \operatorname{Pr}\left(R_{t}^{n}<1\right)$, which we set at 0.01 , and corresponds to a value of the

\footnotetext{
${ }^{6}$ For the remainder of the optimal monetary policy analysis we shut down stochastic monetary policy innovations, that is why no random term is included in (33).
} 
penalty parameter $w_{r}=80$.

We optimize the interest rate rule (33) by numerically searching for the combination of the policy parameters and the weight on durables inflation $\tau \in[0,1]$ that maximizes the present value of households' utility (34). In doing so, the support of $\rho_{R}$ is $[0,1]$ whereas the support of $\alpha_{\pi}, \alpha_{y}$ and $\alpha_{\Delta y}$ is $[0,5]$. Then, we assess the role of labor mobility by considering three cases: (i) $\lambda=0.25$ represents the case of quasi labor immobility, (ii) $\lambda=\infty$ the case of perfect labor mobility and (iii) $\lambda=1.1769$, the imperfect labor mobility estimated in Section 3. Then we compare the welfare losses in terms of steady-state consumption-equivalent, $\omega$, with respect to the Ramsey policy, as in Schmitt-Grohe and Uribe (2007). In particular, for a regime associated to a given Taylor-type interest rate rule A, the welfare loss is implicitly defined as

$$
E_{0}\left\{\sum_{t=0}^{\infty} \beta^{t}\left[U\left((1-\omega) X_{t}^{R}, N_{t}^{R}\right)\right]\right\}=E_{0}\left\{\sum_{t=0}^{\infty} \beta^{t}\left[U\left(X_{t}^{A}, N_{t}^{A}\right)\right]\right\},
$$

where $\omega \times 100$ represents the percent permanent loss in consumption that should occur in the Ramsey regime $(R)$ in order for agents to be as well off in regime $R$ as they are in regime $\mathrm{A}$.

\subsection{Results}

\subsubsection{Impulse responses to an inflation shock}

We first graphically explore how different degrees of labor mobility alter the optimal responses to structural shocks. Figure 2 shows the responses to an inflation shock (namely a shock to the price mark-up) under the Ramsey policy and sticky durables prices. Higher mark-ups in the durables sector increase inflation and decrease investment and employment in durables for any degree of labor mobility. However, when labor is prevented from moving across sectors, output and employment fall also in nondurables. Indeed, although households would substitute durables with nondurables, firms in the nondurables sector are not able to hire workers from the durables sector and increase production. It follows that output in both sectors decreases and aggregate output is persistently below the steady-state.

Conversely, when labor is mobile, consumption in nondurables increases since labor

can flow from the durables sector. Output in the two sectors displays a negative comovement and the response of durables is more gradual. This makes aggregate 

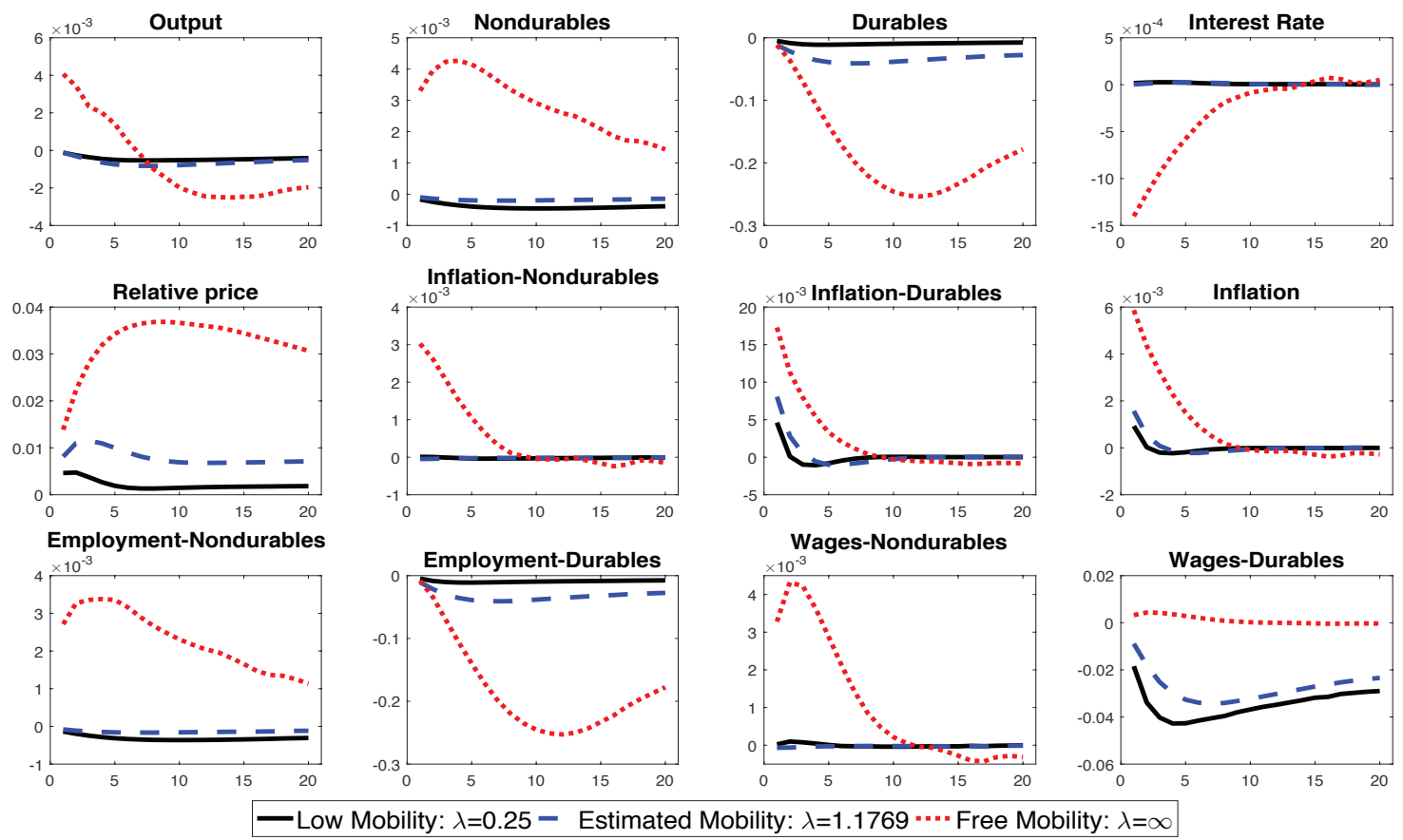

Figure 2: Responses to a durables price markup shock: Ramsey policy

output increase in the first seven quarters, i.e. when the positive effect on nondurables output outweighs the fall in durables. Later on, the stronger decline of durables takes over and aggregate output falls. Moreover, the optimal response of the nominal interest rate is significantly different when labor is perfectly mobile: i.e. it accommodates the increase in inflation. ${ }^{7}$ The intuition is that a fall in the nominal interest rate stimulates consumption in nondurables and, since more workers can flow from the durable to the nondurable sector, supply will be able to catch up with demand and avoid a recession, at least in the first seven quarters after the shock. This suggests that labor mobility has important implications for the transmission mechanism of structural shocks and optimal monetary policy.

\subsubsection{Optimized interest-rate rules}

Turning to the welfare properties of the interest rate rule (33), Table 3 reports its optimized parameters together with the associated welfare costs $\omega$. The top panel displays the optimized parameters in the baseline model in which all the parameters

\footnotetext{
${ }^{7}$ The procyclical behavior of the nominal interest rate will be important in our analysis as explained in the next section.
} 


\begin{tabular}{ccccccc}
\hline$\lambda$ & $\rho_{R}$ & $\alpha_{\pi}$ & $\alpha_{y}$ & $\alpha_{\Delta y}$ & $\tau$ & $\omega$ \\
\hline \multicolumn{7}{c}{ Sticky durables prices } \\
0.25 & 1 & 0.0633 & 0.0000 & 0.0109 & 0.4831 & 0.0716 \\
1.1769 & 1 & 0.1104 & 0.0000 & 0.0191 & 0.1612 & 0.0846 \\
$\infty$ & 1 & 0.4611 & 0.0000 & 0.0000 & 0.0000 & 0.5947 \\
& \multicolumn{1}{c}{ Flexible durables prices } \\
0.25 & 1 & 0.0404 & 0.0000 & 0.0135 & 0.1581 & 0.0791 \\
1.1769 & 1 & 0.1000 & 0.0000 & 0.0187 & 0.0000 & 0.0920 \\
$\infty$ & 1 & 0.5055 & 0.0000 & 0.0000 & 0.0000 & 0.9572 \\
\hline
\end{tabular}

Table 3: Optimized monetary policy rule: Sticky vs Flexible Durables Prices

(except $\lambda$ and those that are optimally set), are calibrated at the posterior means reported in Section 3.

We first notice that regardless of the degree of labor mobility, the central bank response to the output gap and output gap growth is absent whereas a stronger reaction is devoted to inflation, a result in line with the findings of Schmitt-Grohe and Uribe (2007) in a one-sector model. Moreover, the interest rate smoothing parameter systematically hits the upper bound of one, thus characterizing (33) as a price-level rule. As discussed by Giannoni (2014), price-level rules deliver better welfare results than Taylor-type rule by introducing a sufficient amount of history dependence in an otherwise entirely forward-looking behavior of price setters, thus reducing the volatility of inflation. It is therefore not surprising that the optimal value of $\rho_{R}$ equals $1 .^{8}$

Along these results, here the novel finding concerns the inverse relationship that arises between the optimal weight placed on durables inflation $\tau$ and sectoral labor mobility. Uniformly, the higher weight in the inflation composite is assigned to nondurables $(\tau<0.5)$, as this is the sector with the higher price stickiness. However, an inverse relationship between sectoral labor mobility and the optimal weight placed on durables inflation arises. As labor becomes more mobile (i.e. $\lambda$ increases) the central bank finds it optimal to place even less weight on durables inflation (i.e. optimal $\tau$ decreases). Indeed, when labor is perfectly mobile $(\lambda=\infty)$, no weight is assigned

\footnotetext{
${ }^{8}$ Similar results hold in other contexts, such as the New-Keynesian model with financial frictions studied by Melina and Villa (2015).
} 


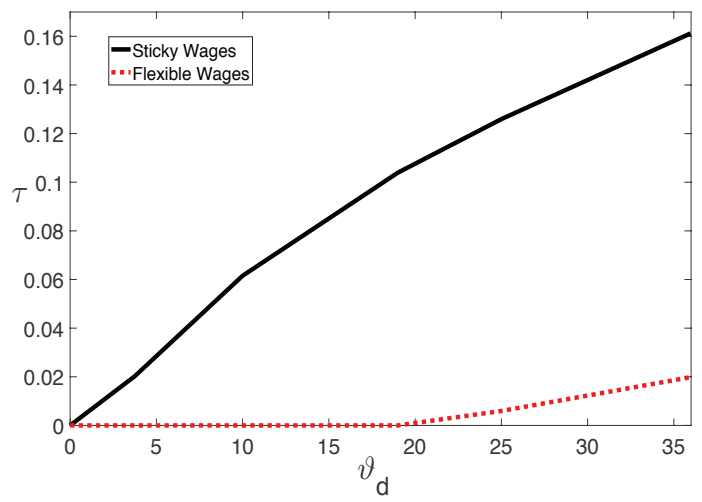

Figure 3: Durables price stickiness and optimal weight on durables inflation: flexible vs. sticky wages

at all. The intuition is that, with more mobile labor, adjustments to shocks easily occur through quantities (via the reallocation of labor itself) rather than prices, and the central bank finds it optimal to focus more on the sector with the higher price stickiness.

The lower panel of Table 3 shows that these results hold also when prices of durables are assumed to be flexible $\left(\vartheta^{d}=0\right)$. Interestingly, for a sufficiently limited degree of labor mobility, $\tau$ is still nonzero. This result is driven by nominal wage stickiness. In fact, wage stickiness affects firms' marginal costs and their price setting behavior. The pass-through of sticky wages to the durables sector marginal cost induces the central bank to place some weight on inflation in this sector despite price flexibility. Figure 3 shows the relationship between the optimal $\tau$ and durables price stickiness, $\vartheta^{d}$, under sticky and flexible wages. ${ }^{9}$ We notice that $\tau$ is a strictly increasing function of $\vartheta^{d}$ when wages are sticky. Even when durables prices are very flexible ( $\vartheta^{d}$ approaches zero), the optimal weight on durables inflation is positive. ${ }^{10}$ Conversely, with flexible wages a sufficiently high degree of durables price stickiness is needed for the central bank to place a positive weight on durables inflation.

Comparing the welfare losses with respect to the Ramsey policy (Table 3), we notice that when labor becomes perfectly mobile, the welfare loss is higher than in the cases of limited labor mobility. This is due to the procyclical optimal behavior of the nominal interest rate under the Ramsey policy and perfect labor mobility, which by construction

\footnotetext{
${ }^{9}$ Labor mobility is limited at the estimated value of $\lambda=1.1769$.

${ }^{10}$ As sectoral labor mobility decreases, this result is exacerbated. Indeed, the lower panel of Table 3 shows that with low mobility and fully flexible durables prices the optimal weight on durables inflation is substantially positive.
} 


\begin{tabular}{cccc}
\hline$\lambda$ & $\Delta_{\Pi}$ & $\Delta_{W}$ & $\Delta_{Y}$ \\
\hline 0.25 & 1.9089 & 6.4104 & 1.6591 \\
1.1769 & 1.9611 & 4.7002 & 4.3077 \\
$\infty$ & 6.6898 & 1 & 22.2308 \\
\hline
\end{tabular}

Table 4: Relative standard deviations of inflation, wages and output

cannot be replicated by the simple interest rate rules. ${ }^{11}$

Implied relative volatilities in these exercises confirm existing findings in the literature and add further insights. In particular, Table 4 reports the standard deviation of durables inflation, wages and output relative to nondurables in the baseline model and under different degrees of labor mobility. In all cases the volatility of sectoral prices, wages and output in the durables sector is larger than in nondurables, which extends the results that Erceg and Levin (2006) obtain in a model with no sectoral labor mobility to a model with limited or perfect mobility. Obviously, under perfect labor mobility wages are the same in the two sectors, hence there is no difference in their volatility. In contrast, under limited labor mobility, the standard deviation of wages in durables is always larger than nondurables (about 4.7 times under the estimated degree of labor mobility) with this difference increasing as labor mobility decreases and adjustments to shocks occur predominantly through wages rather than the reallocation of labor. Conversely, the relative volatilities of prices and output in the two sectors are increasing functions of the degree of labor mobility (variables in the durables sector become much more volatile than in nondurables).

All in all, our results reveal that the degree at which workers are able to reallocate across sectors is crucial for the optimal design of monetary policy, and an inverse relationship exists between sectoral labor mobility and the importance of the sector which displays relatively more flexible prices. Wage stickiness, via its substantial passthrough onto marginal costs, leads to a non-zero optimal weight on durables inflation even if durables prices were fully flexible.

\footnotetext{
${ }^{11}$ Figure 2 is an example of the optimal procyclicality of the nominal interest rate. Under perfect labor mobility, the social planner decreases the nominal interest rate despite the increase in inflation. Such behavior holds under the other structural shocks of the model and impulse responses are available upon request.
} 


\begin{tabular}{ccccccc}
\hline$\lambda$ & $\rho_{R}$ & $\alpha_{\pi}$ & $\alpha_{y}$ & $\alpha_{\Delta y}$ & $\tau$ & $\omega$ \\
\hline \multicolumn{7}{c}{ Flexible wages } \\
0.25 & 1 & 0.1570 & 0.0000 & 0.0000 & 0.1765 & 0.0274 \\
1.1769 & 1 & 0.2254 & 0.0000 & 0.0000 & 0.0214 & 0.0095 \\
$\infty$ & 1 & 0.4829 & 0.0000 & 0.0000 & 0.0000 & 0.0593 \\
& \multicolumn{1}{c}{ Flexible durables prices and wages } & \\
0.25 & 1 & 0.1298 & 0.0000 & 0.0000 & 0.0216 & 0.0286 \\
1.1769 & 1 & 0.2426 & 0.0000 & 0.0000 & 0.0000 & 0.0101 \\
$\infty$ & 1 & 0.4962 & 0.0000 & 0.0000 & 0.0000 & 0.1104 \\
\hline
\end{tabular}

Table 5: Optimized monetary policy rules: robustness to alternative calibrations

\subsection{Robustness to alternative calibrations and interest rate rules}

In this section we perform two types of robustness checks. We first look at the implications of two alternative calibrations of price and wage stickiness. Then, we replace the monetary policy rule (33) with two alternative rules and compare the results with the baseline model.

The top panel of Table 5 shows the case of flexible wages $\left(\vartheta^{W}=0\right)$ whereas in the lower panel both durables prices and wages are flexible $\left(\vartheta_{d}=\vartheta^{W}=0\right)$. As shown in Figure 3, at the estimated limited degree of labor mobility the optimal weight on durables inflation drops as wages become flexible ( $\tau$ falls from 0.1612 to 0.0214 ) and becomes zero as both frictions are removed. The main conclusions drawn in the previous section are carried over these two alternative calibrations: i) $\tau$ and $\lambda$ are negatively related hence a lower weight is assigned to durables inflation as labor becomes mobile; ii) the central bank finds it optimal to implement a price-level rule $\left(\rho_{R}=1\right)$.

As the optimal degree of interest rate inertia systematically hits the upper bound, it is natural to ask what would happen should we allow $\rho_{R}$ to be larger than 1 . Interest rate rules as equation (33) with $\rho_{R}>1$ are usually referred to as superinertial rules and have the desirable feature of adding further history dependence in policy as explained by Giannoni and Woodford (2003) and Giannoni (2014). The top panel of table 6 reports the optimized parameters of the baseline model when rule (33) can be superinertial, with $\rho_{R} \in[0,5]$. It is noteworthy that for any degree of labor mobility: i) the central bank optimally chooses a superinertial rule, with $\rho_{R}$ hitting the upper bound as labor 


\begin{tabular}{ccccccc}
\hline$\lambda$ & $\rho_{R}$ & $\alpha_{\pi}$ & $\alpha_{y}$ & $\alpha_{\Delta y}$ & $\tau$ & $\omega$ \\
\hline \multicolumn{7}{c}{ Superinertial rule } \\
0.25 & 1.2987 & 0.0313 & 0.0022 & 0.0166 & 0.3405 & 0.0491 \\
1.1769 & 5 & 1.5372 & 0.0150 & 0.9426 & 0.0700 & 0.0196 \\
$\infty$ & 5 & 4.1027 & 0.0000 & 0.0000 & 0.0000 & 0.4024 \\
& & & Implementable rule & & \\
0.25 & 1 & 0.0595 & 0.0000 & $\backslash$ & 0.5590 & 0.0727 \\
1.1769 & 1 & 0.1177 & 0.0000 & $\backslash$ & 0.2248 & 0.0857 \\
$\infty$ & 1 & 0.4618 & 0.0000 & $\backslash$ & 0.0000 & 0.5945 \\
\hline
\end{tabular}

Table 6: Robustness to alternative optimized monetary policy rule

becomes more mobile; ii) the welfare losses with respect to the Ramsey policy are smaller with respect to the price-level rules; iii) crucially, the negative relationship between labor mobility and the optimal weight on durables inflation survives.

We then replace rule (33) with an interest rate rule that responds only to inflation and the deviation of output from its steady state. Following Schmitt-Grohe and Uribe (2007) this type of interest rate rule is typically labelled implementable rule and, after the appropriate reparametrization, reads as follows:

$$
\log \left(\frac{R_{t}}{\bar{R}}\right)=\rho_{r} \log \left(\frac{R_{t-1}}{\bar{R}}\right)+\alpha_{\pi} \log \left(\frac{\tilde{\Pi}_{t}}{\tilde{\Pi}}\right)+\alpha_{y} \log \left(\frac{Y_{t}}{\bar{Y}}\right),
$$

where $\alpha_{\pi} \equiv\left(1-\rho_{r}\right) \rho_{\pi}, \alpha_{y} \equiv\left(1-\rho_{r}\right) \rho_{y}$. The lower panel of Table 6 demonstrates that despite these modifications, the choice towards a price-level rule and the inverse relationship between labor mobility and the optimal weight on durables inflation still hold true. In addition, the implied welfare losses are similar to the baseline model.

\section{Conclusion}

As the New-Keynesian literature on two-sector models has demonstrated, setting the appropriate weights to sectoral inflations is a crucial task for a central bank in order to achieve its objectives. We look at this issue from an angle the literature has so far overlooked. In particular, we study the relation between the degree of sectoral 
labor mobility and the optimal weight the central bank should assign to inflation in the sector with relatively more flexible prices (durables). We first estimate the model with Bayesian methods and find evidence of a limited sectoral labor mobility. Then, we exploit the estimated model to perform optimal monetary policy analysis. Under the Ramsey policy, the optimal responses to structural shocks are significantly altered by different degrees of sectoral labor mobility. Preventing labor from moving freely between sectors dramatically changes the optimal path of the policy rate, thus leading to different effects on sectoral and aggregate variables, as well as on welfare.

We then let the central bank optimize the parameters of a simple monetary policy rule along with the weight on inflation in the durables sector for different degrees of labor mobility. Our main result is that conditional on the intensity of price stickiness in the durables sector, an inverse relationship between labor mobility and the optimal weight on the sector with relatively more flexible prices arises: a lower weight is assigned to durables inflation as the degree of labor mobility increases. Intuitively, with more mobile labor, adjustments to shocks easily occur through quantities (via the reallocation of labor itself) rather than prices, and the the central bank finds it optimal to focus more on the sector with the higher price stickiness.

Wage stickiness also plays an important role on the optimal weight of durables inflation. Via the pass-through on marginal costs it always implies a higher weight on durables inflation with respect to the case of flexible wages. In the design of optimal monetary policy, we also find that the central bank chooses to implement a price-level rule by introducing desirable history dependence in the model to reduce the volatility of prices, thus confirming results the literature has found in one-sector models.

These results are confirmed by various robustness checks and point to a nonnegligible role of sectoral labor mobility for the conduct of monetary policy.

\section{References}

Aoki, K. (2001). Optimal monetary policy responses to relative-price changes. Journal of Monetary Economics, 48(1):55-80.

Barsky, R. B., House, C. L., and Kimball, M. S. (2007). Sticky-price models and durable goods. American Economic Review, 97(3):984-998.

Benigno, P. (2004). Optimal monetary policy in a currency area. Journal of International Economics, 63(2):293-320. 
Bils, M. and Klenow, P. J. (2004). Some evidence on the importance of sticky prices. Journal of Political Economy, 112(5):947-985.

Bouakez, H., Cardia, E., and Ruge-Murcia, F. (2014). Sectoral price rigidity and aggregate dynamics. European Economic Review, 65(C):1-22.

Bouakez, H., Cardia, E., and Ruge-Murcia, F. J. (2009). The transmission of monetary policy in a multisector economy. International Economic Review, 50(4):1243-1266.

Bouakez, H., Cardia, E., and Ruge-Murcia, F. J. (2011). Durable goods, intersectoral linkages and monetary policy. Journal of Economic Dynamics and Control, $35(5): 730-745$.

Cantelmo, A. and Melina, G. (2015). Monetary Policy and the Relative Price of Durable Goods. CESifo Working Paper Series 5328, CESifo Group Munich.

Cantore, C., Levine, P., Melina, G., and Yang, B. (2012). A fiscal stimulus with deep habits and optimal monetary policy. Economics Letters, 117(1):348-353.

Christiano, L. J., Eichenbaum, M., and Evans, C. L. (2005). Nominal rigidities and the dynamic effects of a shock to monetary policy. Journal of Political Economy, $113(1): 1-45$.

Di Pace, F. and Hertweck, M. (2016). Labour market frictions, monetary policy and durable goods. Bank of England working papers 623, Bank of England.

Erceg, C. and Levin, A. (2006). Optimal monetary policy with durable consumption goods. Journal of Monetary Economics, 53(7):1341-1359.

Gerberding, C., Gerke, R., and Hammermann, F. (2012). Price-level targeting when there is price-level drift. Journal of Macroeconomics, 34(3):757-768.

Giannoni, M. P. (2014). Optimal interest-rate rules and inflation stabilization versus price-level stabilization. Journal of Economic Dynamics and Control, 41(C):110-129.

Giannoni, M. P. and Woodford, M. (2003). Optimal Interest-Rate Rules: I. General Theory. NBER Working Papers 9419, National Bureau of Economic Research, Inc.

Horvath, M. (2000). Sectoral shocks and aggregate fluctuations. Journal of Monetary Economics, 45(1):69-106.

Huang, K. X. and Liu, Z. (2005). Inflation targeting: What inflation rate to target? Journal of Monetary Economics, 52(8):1435-1462.

Iacoviello, M. and Neri, S. (2010). Housing market spillovers: Evidence from an estimated DSGE model. American Economic Journal: Macroeconomics, 2(2):125-64.

Jeske, K. and Liu, Z. (2013). Should The Central Bank Be Concerned About Housing Prices? Macroeconomic Dynamics, 17(01):29-53. 
Kara, E. (2010). Optimal monetary policy in the generalized Taylor economy. Journal of Economic Dynamics and Control, 34(10):2023-2037.

Levine, P., McAdam, P., and Pearlman, J. (2008). Quantifying and sustaining welfare gains from monetary commitment. Journal of Monetary Economics, 55(7):1253-1276.

Mankiw, N. G. and Reis, R. (2003). What Measure of Inflation Should a Central Bank Target? Journal of the European Economic Association, 1(5):1058-1086.

Melina, G. and Villa, S. (2015). Leaning Against Windy Bank Lending. CESifo Working Paper Series 5317, CESifo Group Munich.

Monacelli, T. (2008). Optimal monetary policy with collateralized household debt and borrowing constraints. In Asset Prices and Monetary Policy, NBER Chapters, pages 103-146. National Bureau of Economic Research, Inc.

Monacelli, T. (2009). New Keynesian models, durable goods, and collateral constraints. Journal of Monetary Economics, 56(2):242-254.

Nakamura, E. and Steinsson, J. (2008). Five facts about prices: A reevaluation of menu cost models. The Quarterly Journal of Economics, 123(4):1415-1464.

Petrella, I., Rossi, R., and Santoro, E. (2016). Monetary policy with sectoral trade-offs. mimeo.

Petrella, I. and Santoro, E. (2011). Input-output interactions and optimal monetary policy. Journal of Economic Dynamics and Control, Elsevier, 35(11):1817-1830.

Rotemberg, J. J. (1982). Monopolistic price adjustment and aggregate output. Review of Economic Studies, 49(4):517-31.

Schmitt-Grohe, S. and Uribe, M. (2007). Optimal simple and implementable monetary and fiscal rules. Journal of Monetary Economics, 54(6):1702-1725.

Smets, F. and Wouters, R. (2007). Shocks and frictions in US business cycles: A Bayesian DSGE approach. American Economic Review, 97(3):586-606.

Strum, B. E. (2009). Monetary Policy in a Forward-Looking Input-Output Economy. Journal of Money, Credit and Banking, 41(4):619-650.

Woodford, M. (2003). Interest and Prices. Foundations of a Theory of Monetary Policy. Princeton University Press, Princeton, NJ.

Zubairy, S. (2014). On fiscal multipliers: Estimates from a medium scale DSGE model. International Economic Review, 55:169-195. 


\section{Appendix}

\section{A Data}

We define the durables sector as the a composite of durable goods and residential investments whereas the nondurables sector comprises nondurables goods and services.

\begin{tabular}{|c|c|c|c|}
\hline Series & Definition & Source & Mnemonic \\
\hline$D U R^{N}$ & Nominal Durable Goods & BEA & Table 2.3.5 Line 3 \\
\hline$R I^{N}$ & Nominal Residential Investment & BEA & Table 1.1.5 Line 13 \\
\hline$N D^{N}$ & Nominal Nondurable Goods & BEA & Table 2.3.5 Line 8 \\
\hline$S^{N}$ & Nominal Services & BEA & Table 2.3.5 Line 13 \\
\hline$P_{D U R}$ & Price Deflator, Durable Goods & BEA & Table 1.1.9 Line 4 \\
\hline$P_{R I}$ & Price Deflator, Residential Investment & BEA & Table 1.1.9 Line 13 \\
\hline$P_{N D}$ & Price Deflator, Nondurable Goods & BEA & Table 1.1.9 Line 5 \\
\hline$P_{S}$ & Price Deflator, Services & BEA & Table 1.1.9 Line 6 \\
\hline$Y^{N}$ & Nominal GDP & BEA & Table 1.1.5 Line 1 \\
\hline$P_{Y}$ & Price Deflator, GDP & BEA & Table 1.1.9 Line 1 \\
\hline$F F R$ & Effective Federal Funds Rate & FRED & FEDFUNDS \\
\hline$N$ & Nonfarm Business Sector: Average Weekly Hours & FRED & PRS85006023 \\
\hline$W$ & Nonfarm Business Sector: Compensation Per Hour & FRED & COMPNFB \\
\hline$P O P$ & Civilian Non-institutional Population, over 16 & FRED & CNP16OV \\
\hline$C E$ & Civilian Employment, 16 over & FRED & CE16OV \\
\hline
\end{tabular}

Table A.1: Data Sources

\section{A.1 Durables and Residential Investments}

1. Sum nominal series: $D U R^{N}+R I^{N}=D R^{N}$

2. Calculate sectoral weights of deflators: $\omega^{D}=\frac{D U R^{N}}{D R^{N}} ; \omega^{R I}=\frac{R I^{N}}{D R^{N}}$

3. Calculate Deflator: $P_{D}=\omega^{D} P_{D U R}+\omega^{R I} P_{R I}$ 
4. Calculate Real Durable Consumption: $D=\frac{D U R^{N}+R I^{N}}{P_{D}}$

\section{A.2 Nondurables and Services}

1. Sum nominal series: $N D^{N}+S^{N}=N S^{N}$

2. Calculate sectoral weights of deflators: $\omega^{N D}=\frac{N D^{N}}{N S^{N}} ; \omega^{S}=\frac{S^{N}}{N S^{N}}$

3. Calculate Deflator: $P_{C}=\omega^{N D} P_{N D}+\omega^{S} P_{S}$

4. Calculate Real Nondurable Consumption: $C=\frac{N D^{N}+S^{N}}{P_{C}}$

\section{A.3 Data transformation for Bayesian estimation}

\begin{tabular}{clc}
\hline Variable & Description & Construction \\
\hline$P O P_{\text {index }}$ & Population index & $\frac{P O P}{P O P_{2009: 1}}$ \\
$C E_{\text {index }}$ & Employment index & $\frac{C E}{C E_{2009: 1}}$ \\
$Y^{o}$ & Real per capita GDP & $\ln \left(\frac{\frac{Y^{N}}{P Y}}{P O P_{\text {index }}}\right) 100$ \\
$I_{D}^{o}$ & Real per capita consumption: durables & $\ln \left(\frac{D}{P O P_{\text {index }}}\right) 100$ \\
$C^{o}$ & Real per capita consumption: nondurables & $\ln \left(\frac{C}{P O P_{\text {index }}}\right) 100$ \\
$W^{o}$ & Real wage & $\ln \left(\frac{W}{P_{Y}}\right) 100$ \\
$N^{o}$ & Hours worked per capita & $\ln \left(\frac{H \times C E_{i n d e x}}{P O P_{\text {index }}}\right) 100$ \\
$\Pi_{C}^{o}$ & Inflation: nondurables sector & $\Delta\left(\ln P_{C}\right) 100$ \\
$\Pi_{D}^{o}$ & Inflation: durables sector & $\Delta\left(\ln P_{D}\right) 100$ \\
$R^{o}$ & Quarterly Federal Funds Rate & $\frac{F F R}{4}$ \\
\hline
\end{tabular}

Table A.2: Data transformation - Observables 


\section{B Symmetric equilibrium}

$$
\begin{aligned}
& X_{t}=Z_{t}^{1-\alpha} D_{t}^{\alpha} \\
& Z_{t}=C_{t}-\zeta S_{t-1} \\
& S_{t}=\rho_{c} S_{t-1}+\left(1-\rho_{c}\right) C_{t} \\
& U\left(X_{t}, N_{t}\right)=\log \left(X_{t}\right)-\nu \frac{N_{t}^{1+\varphi}}{1+\varphi} \\
& U_{Z, t}=\frac{(1-\alpha)}{Z_{t}} \\
& U_{D, t}=\frac{\alpha}{D_{t}} \\
& U_{N, t}=-\nu N_{t}^{\varphi} \\
& N_{t}=\left[\left(\chi^{C}\right)^{-\frac{1}{\lambda}}\left(N_{t}^{C}\right)^{\frac{1+\lambda}{\lambda}}+\left(1-\chi^{C}\right)^{-\frac{1}{\lambda}}\left(N_{t}^{D}\right)^{\frac{1+\lambda}{\lambda}}\right]^{\frac{\lambda}{1+\lambda}} \\
& N_{t}^{C}=\chi^{C}\left(\frac{w_{t}^{C}}{w_{t}}\right)^{\lambda} N_{t} \\
& N_{t}^{D}=\chi^{D}\left(\frac{w_{t}^{D}}{w_{t}}\right)^{\lambda} N_{t} \\
& \Lambda_{t, t+1} \equiv \beta \frac{U_{Z, t+1}}{U_{Z, t}} \frac{e_{t+1}^{B}}{e_{t}^{B}} \\
& {\left[1-e_{t}^{W} \eta\right]+\frac{e_{t}^{W} \eta}{\tilde{\mu}_{t}}=\vartheta^{W}\left(\Pi_{t}^{W}-\Pi^{C}\right) \Pi_{t}^{W}+} \\
& +E_{t}\left[\Lambda_{t, t+1} \vartheta^{W}\left(\Pi_{t+1}^{W}-\Pi^{C}\right) \Pi_{t+1}^{W} \frac{w_{t+1} N_{t+1}}{w_{t} N_{t}}\right] \\
& \tilde{\mu}_{t}=-\frac{U_{Z, t}}{U_{N, t}} w_{t} \\
& Q_{t} \psi_{t}=\frac{U_{D, t}}{U_{Z, t}}+(1-\delta) E_{t}\left[\Lambda_{t, t+1} Q_{t+1} \psi_{t+1}\right] \\
& 1=\psi_{t} e_{t}^{I}\left[1-S\left(\frac{I_{t}^{D}}{I_{t-1}^{D}}\right)-S^{\prime}\left(\frac{I_{t}^{D}}{I_{t-1}^{D}}\right) \frac{I_{t}^{D}}{I_{t-1}^{D}}\right]+ \\
& +E_{t}\left\{\Lambda_{t, t+1} \psi_{t+1} \frac{Q_{t+1}}{Q_{t}} e_{t+1}^{I}\left[S^{\prime}\left(\frac{I_{t+1}^{D}}{I_{t}^{D}}\right)\left(\frac{I_{t+1}^{D}}{I_{t}^{D}}\right)^{2}\right]\right\}
\end{aligned}
$$




$$
\begin{aligned}
& S\left(\frac{I_{t}^{D}}{I_{t-1}^{D}}\right)=\frac{\phi}{2}\left(\frac{I_{t}^{D}}{I_{t-1}^{D}}-1\right)^{2} \\
& S^{\prime}\left(\frac{I_{t}^{D}}{I_{t-1}^{D}}\right)=\phi\left(\frac{I_{t}^{D}}{I_{t-1}^{D}}-1\right) \\
& 1=E_{t}\left[\Lambda_{t, t+1} \frac{R_{t}}{\Pi_{t+1}^{C}}\right] \\
& \Pi_{t}^{D}=\Pi_{t}^{C} \frac{Q_{t}}{Q_{t-1}} \\
& \Pi_{t}^{W}=\frac{w_{t}}{w_{t-1}} \widetilde{\Pi}_{t} \\
& Y_{t}^{C}=e_{t}^{A} N_{t}^{C} \\
& Y_{t}^{D}=e_{t}^{A} N_{t}^{D} \\
& \left(1-e_{t}^{C} \epsilon_{c}\right)+e_{t}^{C} \epsilon_{c} M C_{t}^{C}=\vartheta_{c}\left(\Pi_{t}^{C}-\Pi^{C}\right) \Pi_{t}^{C}- \\
& -\vartheta_{c} E_{t}\left[\Lambda_{t, t+1} \frac{Y_{t+1}^{C}}{Y_{t}^{C}}\left(\Pi_{t+1}^{C}-\Pi^{C}\right) \Pi_{t+1}^{C}\right] \\
& M C_{t}^{C}=\frac{w_{t}}{e_{t}^{A}} \\
& \left(1-e_{t}^{D} \epsilon_{d}\right)+e_{t}^{D} \epsilon_{d} M C_{t}^{D}=\vartheta_{d}\left(\Pi_{t}^{D}-\Pi^{D}\right) \Pi_{t}^{D}- \\
& -\vartheta_{d} E_{t}\left[\Lambda_{t, t+1} \frac{Q_{t+1}}{Q_{t}} \frac{Y_{t+1}^{D}}{Y_{t}^{D}}\left(\Pi_{t+1}^{D}-\Pi^{D}\right) \Pi_{t+1}^{D}\right] \\
& M C_{t}^{D}=\frac{w_{t}}{e_{t}^{A} Q_{t}} \\
& \widetilde{\Pi}_{t}=\left(\Pi_{t}^{C}\right)^{1-\tau}\left(\Pi_{t}^{D}\right)^{\tau} \\
& \log \left(\frac{R_{t}}{\bar{R}}\right)=\left[\rho_{\pi} \log \left(\frac{\Pi_{t}}{\bar{\Pi}}\right)+\rho_{y} \log \left(\frac{Y_{t}}{\bar{Y}}\right)\right]+e_{t}^{M} \\
& Y_{t}^{C}=C_{t}+e_{t}^{G}+\frac{\vartheta_{c}}{2}\left(\Pi_{t}^{C}-\Pi^{C}\right)^{2} Y_{t}^{C} \\
& Y_{t}^{D}=\left[D_{t}-(1-\delta) D_{t-1}\right]+\frac{\vartheta_{d}}{2}\left(\Pi_{t}^{D}-\Pi^{D}\right)^{2} Y_{t}^{D} \\
& Y_{t}=Y_{t}^{C}+Q_{t} Y_{t}^{D}+\frac{\vartheta^{W}}{2}\left(\Pi_{t}^{W}-\Pi^{C}\right)^{2} w_{t} N_{t}
\end{aligned}
$$




\section{Steady state}

In the deterministic steady state all expectation operators are removed and for each variable it holds that $x_{t}=x_{t+1}=x$. Moreover, the stochastic shocks are absent. The steady-state inflation rate in the nondurables sector is the optimal under the Ramsey policy and is denoted by $\Pi_{\mathrm{opt}}^{C}$. $C$ solves equation (65) whereas all other variables can be found recursively from the following relationships:

$$
\begin{aligned}
& \Pi^{D}=\Pi_{\mathrm{opt}}^{C} \\
& \tilde{\Pi}=\Pi_{\mathrm{opt}}^{C} \\
& \Pi^{W}=\Pi_{\mathrm{opt}}^{C} \\
& \Lambda=\beta \\
& R=\frac{1}{\beta} \\
& M C_{t}^{C}=\frac{\epsilon_{c}-1}{\epsilon_{c}} \\
& w^{C}=M C^{C} e^{A} \\
& w^{D}=w^{C} \\
& w=w^{D} \\
& M C_{t}^{D}=\frac{\epsilon_{d}-1}{\epsilon_{d}} \\
& Q=\frac{w^{D}}{M C^{D} e^{A}} \\
& S=0 \\
& S^{\prime}=0 \\
& \psi=1 \\
& \tilde{\mu}=\frac{\eta}{\eta-1} \\
& S=C \\
& Z=(1-\zeta) C \\
& U_{Z}=\frac{(1-\alpha)}{Z} \\
& U_{D}=U_{z} Q \psi[1-(1-\delta) \beta] \\
& D=\frac{\alpha}{U_{D}}
\end{aligned}
$$




$$
\begin{aligned}
U_{N} & =-\frac{U_{Z}}{\tilde{\mu}} w \\
N & =-\left(\frac{U_{N}}{\nu}\right)^{\frac{1}{\varphi}} \\
Y^{D} & =\delta D \\
N^{D} & =Y^{D} \\
N^{C} & =N-N^{D} \\
\chi^{C} & =\frac{N^{C}}{N} \\
e^{G} & =g_{y} Y \\
Y^{C} & =N^{C} \\
X & =Z^{1-\alpha} D^{\alpha}
\end{aligned}
$$

